\title{
Medical Ethics during the COVID-19 Pandemic
}

Sevim Coşkun', [MD, PhD candidate] ORCID: 0000-0003-4509-404X

Nüket Örnek Büken', [MD, PhD] ORCID: 0000-0001-9166-6569

\section{w ABSTRACT Cen}

WHO states five ethical principles for the care of patients with COVID-19: Equal moral respect, duty of care, non-abandonment, protection of the community, and confidentiality. Healthcare professionals might have to make difficult decisions such as selecting patients and withholding or withdrawing mechanical ventilation of critically ill patients. In such difficult situations, a well-prepared action plan which considers ethical principles and prioritizes both public health and the safety of healthcare professionals, can help them. In this case, the development of an effective pandemic action plan, together with a triage plan based on emergency and disaster medicine is necessary. The only parameter of selection in this plan must be the correct application of triage, which respects every human life and depends on the criteria of clinical suitability. In this context, the fundamental ethical principles and human rights must be considered when allocating resources and prioritizing patients. Additionally, all protective measures for healthcare professionals must be taken, including all necessary equipment being adequately provided. If healthcare professionals become infected or face a life-threatening risk, then their obligations will be limited. Therefore, it is necessary to realize these limitations which may arise while providing appropriate health services.

Keywords: COVID-19 pandemic, medical ethics, human rights, the allocation of resources, vulnerable populations

https://doi.org/10.32552/2021.ActaMedica.505

Received: 10 September 2020, Accepted: 16 April 2021

Published online: 7 June 2021

\section{INTRODUCTION}

Novel Coronavirus Disease (COVID-19) was first detected in Wuhan, China, in December 2019. It is caused by a newly emergent coronavirus which is called SARS-CoV-2 [1]. COVID-19 has spread rapidly around the world and it was declared as a pandemic by the World Health Organization (WHO) on March 11, 2020 [2]. As the pandemic continues, many ethical issues have arisen. These ethical issues mainly revolve around how patients with COVID-19 who need critical care can access necessary health services and how to allocate limited resources such as intensive care unit (ICU) beds, ventilators, and medications when there is not enough to treat everyone. Recently, ethical discussions on the distribution of COVID-19 vaccines have become increasingly important since many countries have started their own vaccination programs.
This article will start by covering the ethical principles relating to the care of patients with COVID-19, later provide some examples of the ethical challenges faced during the COVID-19 pandemic, and finish by discussing these challenges in context of the said ethical principles.

\section{Ethical Principles for the Care of Patients with COVID-19}

WHO published an updated clinical management (living) guidance of COVID-19 on 25 January 2021. According to this guidance, WHO aims to slow and stop transmission of COVID-19, provide optimized care for all COVID-19 patients, and minimize the impact of the COVID-19 pandemic on health systems, social services and economic activities. 
Thus, WHO intended to optimize the clinical care of patients with suspected or confirmed COVID-19, and ensure they have the best possible chance of survival. This guidance also includes the ethical principles that are important for the optimal care of patients with COVID-19. As reported by WHO, important ethical considerations in the context of COVID-19 are equal moral respect, duty of care, nonabandonment, protection of the community, and confidentiality [3].

\section{Equal Moral Respect}

Equal moral respect means treating every human being equally, regardless of discriminatory features like age, sex, disability, religion, ethnicity, or political affiliation, so only medical need should be determinative in making treatment and care decisions. Patients who have similar health problems must be given equal treatment and care. Patients and their caregivers also should be in the decision-making process and understand options and limitations in treatment [3].

The right to health, along with the ethical principles surrounding it, is a human right. Article 14 of the UNESCO Universal Declaration on Bioethics and Human Rights says [4, 5]: "the highest attainable standard of health is one of the fundamental rights of every human being without distinction of race, religion, political belief, economic or social condition." Thus, each person should be able to access quality and the highest available healthcare and essential medication.

\subsection{Caregiving for Vulnerable Populations}

Vulnerable populations are prone to easily being abused, affected, and hurt. Vulnerability is related to discrimination, age (children and elderly), gender (girls and women), gender identity and sexual orientation (LGBTI), illness, loss of functionality or autonomy, disability, poverty, imprisonment, ethnicity, undocumented migration, and the status of refugees and stateless persons. Vulnerable persons become even more vulnerable in a pandemic $[4,6]$. UNESCO declares that protecting the vulnerable from any form of stigmatization and discrimination, which can be both verbal and physical, is our collective responsibility. Measures like isolation and quarantine also affect the vulnerable disproportionately [4]. Especially the elderly and the disabled who need intensive care due to COVID-19 may become even more vulnerable. Article 8 of the UNESCO Universal Declaration on Bioethics and Human Rights calls for "respect for human vulnerability and personal integrity", saying that human vulnerability should be considered while applying and developing scientific knowledge, medical practice and associated technologies [5]. This Article gives us fundamental principles that must be respected: human dignity, human rights, and freedoms. In this context, the vulnerable must be protected with regard to their personal integrity, respecting the principles of autonomy, dignity, utility, equality, and justice $[5,6]$.

The COVID-19 pandemic is affecting the elderly and the disabled in particular, and increasing their vulnerabilities. This section will therefore cover the vulnerabilities thay face during the pandemic.

\subsection{Caregiving for the Elderly}

Old age is a risk factor for increased mortality in those affected by COVID-19. Since the elderly are often affected by other risk factors such as hypertension, chronic lung disease, and cerebrovascular disease; they are potentially at the highest risk for fatality. They are thus one of the most vulnerable populations in the context of the pandemic $[1,3]$. It is important to realize that the elderly have the same right as others to receive high-quality healthcare, including intensive care, as stated in the principle of equal moral respect. Therefore, they should benefit from health services without any discrimination [7].

WHO recommends that the elderly should be screened for COVID-19 at the first point of access to the healthcare system. If they are suspected to have COVID-19, this should be recognized quickly and treated appropriately, according to established COVID-19 care pathways. This approach should be in all places where the elderly might seek care, including facility-based emergency units, primary care, prehospital care settings, and long-term care facilities (LTCFs). For the elderly with suspected or confirmed COVID-19, person-centered assessment should be provided, including not only conventional history taking, but also a thorough understanding of the person's life, values, priorities, and preferences [1]. Healthcare professionals should identify if there is an advance care plan for older patients with COVID-19 like their desires for intensive care support, also respect their priorities 
and preferences. Likewise, the care plan should be parallel with the expressed wishes of patients, and healthcare professionals should provide the best care regardless of patients' treatment choices [3].

Physiological changes with age lead to declines in the intrinsic capacity such as malnutrition, cognitive decline, and depressive symptoms. Those conditions might interact at several levels and require an integrated approach to the screening, assessment, and management of the elderly. Hearing and vision impairments are more common among older adults and may cause a communication barrier, especially when masks prevent lip reading and decrease vocal clarity. Healthcare professionals should consider cognitive decline, too, when communicating with older patients. Healthcare professionals should also identify those impairments as early as possible for adjusting their communication in older patients' care [3].

There should be multidisciplinary collaboration among physicians, nurses, pharmacists, physiotherapists, psychologists, social workers, and other healthcare professionals to decide functional decline and multi-morbidity in older patients. Older patients might be with atypical symptoms of COVID-19, including delirium. Healthcare professionals should consider this during the screening process. Healthcare professionals must be sure that chronic infections are diagnosed and treated appropriately in this group. Other infections such as tuberculosis may look like, or coexist with COVID-19. If unrecognized, these chronic infections may cause increased mortality. Older patients with COVID-19, including those admitted to the ICU, treated with protracted oxygen therapy and bed rest, are more likely to experience functional decline and require coordinated rehabilitation care after acute hospitalization. The elderly are also at higher risk of polypharmacy because of newly prescribed medications and a lack of coordination. WHO recommends a review of medication prescriptions to reduce polypharmacy for the elderly with COVID-19, to prevent them from medicine interactions and adverse effects [3].

\subsection{Caregiving for the Disabled}

The European Disability Forum (EDF) published an updated statement on 24 March 2020, entitled "Ethical Medical Guidelines in COVID-19 - Disability Inclusive Response." In this statement, EDF declared that some reports about the medical guidelines for COVID-19 in some countries were extremely worrying because those reports stated that mentioned guidelines are discriminatory against people with disabilities. For this reason, EDF demands non-discriminatory ethical medical guidelines, and explains how they should be prepared. In this context, EDF states that if healthcare professionals cannot provide the same level of care to everyone because of insufficient funds and equipment in some countries, then medical guidelines must follow international law and ethics guidelines for caring in disasters and emergencies. Ethical medical guidelines in COVID-19 must thus be non-discriminatory, and they certainly must not discriminate against people with disabilities [8]. These guidelines also must be compatible with the UN Convention on the Rights of Persons with Disabilities. Particularly Article 11 of the UN Convention which states that "all necessary measures to ensure the protection and safety of persons with disabilities in situations of risk, including situations of armed conflict, humanitarian emergencies and the occurrence of natural disasters" should be taken under international law, including international humanitarian law and international human rights law $[8,9]$.

\section{The Duty of Care}

Under the duty of care principle, it is an ethical and legal responsibility to give each patient the best possible care and treatment under any given circumstances [3]. There exist high risks for everyone in a pandemic, and UNESCO underlines that our right to health can be ensured only by our duty to health both on individual and collective levels [4].

Even if resources have to be allocated during the pandemic, healthcare professionals have a duty of care to ensure the well-being of patients using the resources available. Healthcare professionals also have a right to care, so appropriate Personal Protective Equipment (PPE) and medical equipment must be provided for their safety and well-being $[3,10]$. Healthcare professionals will then be able to support clinical services as long as possible. WHO recommends that healthcare professionals be able to access both appropriate and adequate equipment, and training in caregiving, including IPC (Infection Prevention and Control). Healthcare professionals are at risk for the same types of 
distress as patients, so they should also have access to psychological, social, and spiritual care together with respite and bereavement support when they need it [3].

\subsection{Allocating Limited Healthcare Resources During the COVID-19 Pandemic}

Pandemics make visible the strengths and weaknesses of healthcare systems, they also make visible the obstacles and inequities in access to healthcare in different countries. According to UNESCO, the allocation of resources in health is central to many problems. Political choices at macro-allocation levels have unavoidable results on the micro-allocation of resources in health, and they become even more challenging in a pandemic while the demand for access to treatment is increasing exponentially and rapidly. The effects of choices can easily be seen at patient triage. When there are limited resources, clinical need and effective treatment should be the primary consideration in patient selection. Procedures should be transparent and they should respect human dignity. Both macro and micro allocations of healthcare resources are ethically justified if only they are based on the principle of equity, beneficence, and justice [4].

WHO recommends that health systems prepare plans at local, regional, national, and global levels to be ready to increase clinical care capacity in order to provide appropriate care and maintain essential health services for all COVID-19 patients. Each health institution should also prepare a plan with a clear objective for how to cover the allocation or access to critical medical interventions such as oxygen, intensive care beds, and ventilators. In this context, the objective might be to provide the best possible use of limited resources based upon chosen medical criteria. Such a plan should ensure a fair system of decision-making to allocating resources in place, too. Allocation decisions should then be made according to the plan and regularly reviewed. If necessary, there should be a reallocation of resources where the previous allocation was not proving beneficial. The chosen method for a fair process should use the following procedural principles: inclusiveness, transparency, accountability, and consistency. The main focus should be on the most affected populations for the necessary information. People should easily access the allocation mechanism and understand it at an elementary school level in all major languages in the area. The allocation mechanism should apply allocation principles consistently, and also be available to review the approved triage protocol in light of novel and updated clinical information [3].

\subsection{Triage During the COVID-19 Pandemic}

Triage criteria to apply should be valid for all patients with similar levels of need without considering their COVID-19 status, and also should balance medical utility and equity and ease of implementation [3]. Ethical medical guidelines in COVID-19 should follow the World Medical Association Statement on Medical Ethics in the Event of Disasters for the best practice [8]. According to this statement [10]: "in selecting the patients who may be saved, the physician should consider only their medical status and predicted response to the treatment, and should exclude any other consideration based on non-medical criteria." Likewise, EDF mentions a specific guideline for COVID-19, which is prepared by the Bioethics Committee of the San Marino Republic. This guideline underlines that the fundamental ethical principles must be taken into account when allocating resources and prioritizing patients. The only parameter of selection must be the correct application of triage, which respects every human life and depends on the criteria of clinical suitability. Any other selection criteria would be ranking lives by evaluating them as being more or less worth living. This kind of selection would constitute a violation of human rights, so it is ethically unacceptable $[11,12]$.

World Medical Association (WMA) states that physicians and other healthcare professionals are confronted with exceptional circumstances requiring the continuous need for professionals and the ethical standard of care in disasters. This is necessary for providing treatment to disaster survivors conforms to basic ethical principles without being influenced by other motivations. Insufficient or disrupted medical resources and a large number of patients in a short time bring specific ethical challenges. At the same time, the ethical principles that apply to physicians in such situations should also apply to other healthcare professionals [10].

WMA recommends a system of triage that might be necessary to specify treatment priorities. Although triage usually provides only symptom control 
such as analgesia to some of the patients, those systems are ethical when they adhere to normative standards. The fundamental aspect of triage is demonstrating care and compassion despite the need to allocate limited resources. Authorized and experienced physicians or physician teams that are assisted by competent staff should perform the triage. Since cases may change category, it is necessary to regularly assess the situation during triage [10].

It is ethical for physicians not to persist treating patients "beyond emergency care" at all costs since that would be wasting scarce resources needed elsewhere. The decision to not treat patients due to the peculiar priorities arising from the disaster situation cannot be considered as an ethical or medical failure when it comes to the assistance of a person in mortal danger. It is justified to do so, in order to save a maximum number of lives, but physicians must show compassion and respect for the dignity of such patients. For example, physicians can separate such a patient from others and give appropriate pain relief and sedatives, and also, if possible, ask somebody to stay with the patient and not to leave them alone. After all, physicians must act in consideration of the needs of patients and the available resources. They should give the most appropriate treatment with the patient's consent under the given conditions. Decisions about whom to give priority to in treatment, should be aimed at saving the maximum number of lives and decreasing morbidity to a minimum [10].

\section{Non-abandonment}

The principle of non-abandonment requires that nobody who needs medical care should ever be neglected or abandoned. Care should also contain families and friends of the patients, and options should be explored for maintaining communication with them. All patients with respiratory failure from whom ventilatory support will be withheld or withdrawn should be able to access palliative care. In this respect, palliative care aims to improve the quality of life of patients and their families facing the problems associated with a life-threatening illness like COVID-19. It means prevention and relief of suffering by early identification, assessment, and treatment of physical and psychosocial stressors. Palliative care includes but is not limited to endof-life care and should be with curative treatment. WHO recommends the integration of palliative care and symptom relief into responses to humanitarian emergencies and crises. Hence, necessary palliative care that includes the relief of dyspnea and other symptoms should be given to patients with COVID-19, too, during the pandemic. Palliative care can be provided in any setting and does not require a separate zone in hospitals. Patients should be able to access palliative care at each institution that provides care for people with COVID-19, and efforts should be made to make intervention at home accessible. Furthermore, healthcare professionals should identify if there is an advance care plan for patients with COVID-19 and respect the priorities and preferences of them [3].

In extraordinary conditions like the COVID-19 pandemic, healthcare professionals may have to make very difficult decisions in the frame of bioethics, especially for end-of-life issues. Nevertheless, they should always respect human rights and dignity and adhere to the UNESCO Universal Declaration on Bioethics and Human Rights while making any bioethical evaluation [5, 12].

\section{Protection of the Community}

The protection of the community means there should be an appropriate Infection Prevention and Control (IPC) system that is enforced and respected. This system would protect patients, healthcare professionals, and the whole community. During a pandemic, the main focus should be on both the quality of clinical care for patients and the improvement of public health [3]. In Statement on Covid-19: Ethical Considerations from a Global Perspective, UNESCO states that this challenging COVID-19 pandemic necessitates a global bioethics reflection and response. In this respect, a bioethics perspective with the ethics of science and technology that is rooted in human rights should play a critical role in this pandemic [4].

The UNESCO International Bioethics Committee (IBC) and the UNESCO World Commission on the Ethics of Scientific Knowledge and Technology (COMEST) have declared that we need to concentrate on our common need and shared responsibility to overcome this dramatic situation. The role of bioethics and ethics committees at both national and international levels is to sustain a constructive dialogue with the belief that political decisions need to be both scientifically grounded and ethically guided in such emergencies [4]. 
The IBC and COMEST have highlighted that it is essential to institutionalize a political strategy that prioritizes the health and safety of individuals and the community. This strategy should provide an interdisciplinary open dialogue between science, ethics, law, and politics. It is especially necessary during such a crisis with many unknowns [4]. All information related to public health should be shared by governments timely and accurately. The society should thus be informed and involved in the pandemic process. In this context, governments should avoid the spread of rumors and misinformation that can cause potential panic and discrimination in societies $[10,13]$.

Although political decisions should be made in the frame of sound scientific knowledge, science should not legitimize them alone. In this setting, there are concerns about some policies which are inspired by retrospective analysis of epidemiological data. Some policies such as 'herd immunity' necessitate careful ethical review because they may risk the safety of the general population under uncertain and changing circumstances. Likewise, the herd immunity policy may impact medically unsustainable conditions and the number of lifethreatening cases because of the lack of availability of intensive care units even in developed countries [4].

According to the IBC and COMEST, policies that do not rely on sound scientific knowledge and practices are unethical because they work against building a common reaction to the pandemic [4]. In communities, governments are responsible for public safety, raising the awareness of the public and the protection of health. On the other hand, communities are responsible for abiding by the rules that protect everyone as a community, and healthcare professionals are responsible for treating and caring for patients to preserve public health $[4,10]$.

\section{Confidentiality}

The principle of confidentiality requires that all communication between patient and physician must remain confidential, and private personal data must be kept secure except for public health concerns (surveillance and contact tracing, etc.) or other accepted justifications for breach of confidentiality [3, 13]. WMA also states that physicians have a duty to each patient to ensure confidentiality when dealing with third parties such as filming and social media use. Those must be done only with the explicit consent of each patient. In this regard, physicians must respect patient privacy [10].

\section{DISCUSSION}

The COVID-19 pandemic has shown that people's access to available health services varies depending on how their country is managing the current pandemic. In particular, the health policies and public health approaches of countries are determinant in those changes. In this respect, having a national pandemic plan and developing strategies for the fair allocation of limited resources has gained importance for countries while fighting against COVID-19. Likewise, the number and capacity of intensive care units, the number of available ventilators, the number of healthcare workers and their competence, accessing PPE, necessary medications and vaccines, and solving safety problems have also become very important [13].

There should have been well-structured and applicable national pandemic action plans that are non-discriminatory, that consider basic bioethical principles, and prioritize the public health in each country for minimizing ethical problems [13]. However, there are many examples of ethical challenges faced during the COVID-19 pandemic. Nacoti and his colleagues reported in March that in Italy, their hospital was highly contaminated, and they were far beyond the tipping point. The hospital reserved $70 \%$ of ICU beds for critically ill COVID-19 patients who had a reasonable chance to survive. The waiting period for an intensive care bed was hours long. Older patients were not being resuscitated and died alone without appropriate palliative care. Moreover, the families of the deceased were notified over the phone often by a well-intentioned but exhausted physician with whom they had had no prior contact. Furthermore, the situation in the surrounding area was even worse in Italy. Most hospitals were overcrowded and near collapse. Necessary medications, mechanical ventilators, oxygen, and PPE were not available. Patients were lying on floor mattresses. The healthcare system was also struggling to deliver regular services, and cemeteries were overwhelmed [14]. 
According to Emanuel and his colleagues, there are difficulties in accessing and distributing the necessary resources in many countries. For example, healthcare professionals could not obtain adequate $\mathrm{N}-95$ masks in the United States. PPE requirements for healthcare professionals were downgraded in the United Kingdom and the necessary protective properties of the PPE were not provided. South Korea faced a hospital bed shortage, and some COVID-19 patients died at home while awaiting admission [15]. The Turkish Medical Association (TMA) reported a survey's results in March 2020 that healthcare professionals had difficulties obtaining PPE, such as masks, gloves, and aprons, so they were at high risk for being infected with COVID-19 [16, 17]. TMA also published a statement in August 2020. According to this statement, the COVID-19 pandemic was gradually worsening, and the number of deaths were increasing in Turkey. TMA stated that Turkey's health system had started to become unable to bear this burden, and they were worried about the exhaustion of healthcare professionals while fighting against the pandemic [18]. Likewise, Council of Europe has stated that management of the crisis appears to be fragmented and chaotic in many countries. For example, the elderly in long-term care facilities were neglected or abandoned in Spain, although they were infected. This situation raised many legitimate doubts about whether all of those people, who lost their lives, had access to adequate healthcare, including both lifesaving treatments and end-of-life care to reduce their suffering. There were also disturbing reports coming from different Council of Europe states which described hospitals refusing to admit the elderly since hospitals and emergency healthcare services had become saturated. Moreover, hospitals might have inappropriately refused the elderly even when there were still places available, like in Sweden [19]. Many countries have similarly faced a rapidly increasing imbalance between the supply and demand for medical resources during the pandemic [15].

As mentioned in Article 3 of the Council of Europe Convention on Human Rights and Biomedicine concerning the principle of equity of access to healthcare, it should be kept in mind that everyone, without exception, has the right to the highest attainable standard of health [19]. The statements of UNESCO also make it necessary to act by aiming at the "highest healthcare standard" for all patients with COVID-19. Receiving treatment within this standard should be the fundamental right of every person. Thus, as emphasized before, all patients with COVID-19 must be given the best possible treatment. In this frame, necessary healthcare services should be equal, accessible, and qualified for all, in order to fulfill the right to health, as TMA stated [20].

Physicians and other healthcare professionals are especially important in the pandemic. They should approach the patients with the principle of "first, do no harm." If physicians have to make treatment decisions, they should decide in the frame of their medical knowledge and medical ethics. They should be objective and fair while allocating health resources. Hence, healthcare services should ensure the highest level of safety and justice for patients, complying with professional medical standards during the pandemic [21]. In this process, those who need medical treatment should be informed about the risks, benefits, and alternatives of the proposed treatment, then the patients should make the final decision. However, TMA states that if there would be significant risks for public health in the case of not treating patients, then necessary measures, including isolating the patient, may have to be taken to eliminate those risks to public health. Obtaining consent from patients may not be necessary in such situations [20].

On the other hand, we know that health systems and healthcare professionals are under deep pressure during the COVID-19 pandemic. They often have to make difficult decisions to provide care to patients in difficult conditions. They are extremely busy and under stress. They are also concerned about both the health of themselves and their families. In emergencies, they might have to perform some medical procedures beyond their competence to treat and prevent patients from serious harm. In this context, those procedures might be subjected to consideration in terms of ethical and legal obligations. Also, it should be recognized that obligation to provide healthcare services may have limits. So the working conditions of healthcare professionals, who are in a great struggle during the pandemic, should be reviewed very carefully. Since physicians and other healthcare professionals are at high risk of contracting the disease during the pandemic, the government should protect all healthcare professionals, their families, and those 
who contact them. Suitable working conditions should be provided for healthcare professionals in a way that they would not have to make a choice between the lives of patients and their own lives. Hence, all protective measures must be taken in all workplaces and all necessary equipment adequately provided for them. Moreover, the government and all employers have both legal and ethical responsibilities to protect healthcare professionals. There should be a balance between the duty of care and the taking of risks. If healthcare professionals get infected or face life-threatening risks, then they would be restricted in providing treatment [22]. Therefore, it is necessary to realize these limitations which may arise while providing appropriate health services.

\section{Recommendations and Future Perspectives}

The COVID-19 pandemic is still threatening public health all over the world. Policies which are nondiscriminatory and which prioritize public health should be developed. This would be important in the future as well. Recently, there are some discussions about long COVID in the Lancet [2325]. According to these discussions and WHO [3], long COVID can be defined as the post-COVID syndrome, but there should be a worldwide consensus on terminology and clinical definition of this syndrome. Thus, it would be important to define long COVID and prepare updated guidelines for its correct and ethical management. Longterm health consequences of COVID-19 should be understood better with large and long-term cohort studies and scientific evidence. Diverse populations from different income countries and ethnic groups should be included, too, in those studies. Multidisciplinary, multicentre, and multinational collaborations and approaches would be necessary for data collection. Healthcare professionals must listen to their patients, try to understand their concerns, and manage their symptoms with clear acknowledgment, honest communication, and careful patient-centred research for long COVID. Multidisciplinary healthcare, rehabilitation services, telemedicine and social and financial support would gain importance as well. The capacity of primary care services and adequate occupational health provision would be important for healthcare professionals because of the high burden of long COVID. Certain populations such as the elderly and the disabled might be impacted more by long
COVID-19. So, appropriate actions and protective measures must be taken by the governments to support vulnerable populations. Therefore, action has to be taken against long COVID related problems immediately [23, 26-27]. Also, the discussions about vaccines will continue since many countries focus on vaccination for the pandemic response [23]. UNESCO states that the availability of vaccines for all will take time and require a global effort since many people don't have access to effective treatments and vaccines. Thus, ethics must have a very important role in the prioritization of vaccines. As an unequivocal right, everyone should access adequate health services and treatments, and vaccines should be a global common good. UNESCO rejects vaccine nationalism and defends that it is an essential ethical issue that all people can access vaccines in all countries [28]. Therefore, the regulation, patenting, and ownership rights of vaccines still would be part of ethical discussions.

\section{Limitations}

Since the COVID-19 pandemic is still going on, new ethical issues come up, every day. This review has only covered the major topics related to medical ethics which have arisen during the current pandemic.

\section{CONCLUSION}

In conclusion, some factors such as age, clinical condition, having a comorbid disease, vulnerability, and especially the need for intensive care will strongly affect the patients' quality of life and survival chance during the COVID-19 pandemic. Moreover, available resources and the number of people who have similar needs will be very significant for patients to access the necessary healthcare. Besides, pandemic preparedness in the country and developing effective health policies will be important for providing necessary health services. While delivering healthcare services, both healthcare professionals and patients should have rights based on human rights and the ethical principles of medicine. Also, the action plan for the COVID-19 pandemic should conform to universal ethical principles.

If patients need to be intubated and cared for in $I C U$, the treatment, including palliative and end-oflife care, should be given in a way that is respectful 
to the wishes, decisions, and dignity of patients. Especially for patients who are nearing end of life, healthcare professionals should obtain their consent for the procedures to be performed, if possible, and act in agreement with their end-of-life decisions if they have any. Healthcare professionals also should reduce their pain and suffering and provide for them to spend their last days with dignity and saying goodbye to their relatives. On the other side, health policies should protect healthcare professionals, too. In this context, healthcare professionals should have access to all necessary protective and medical equipment adequately. Healthcare professionals might have to make difficult decisions such as withholding or withdrawing mechanical ventilation of critically ill patients. In such difficult situations, a well-prepared action plan considering ethical principles can help them. Therefore, health policies that are nondiscriminatory and prioritize public health and also the safety of healthcare professionals are necessary for the correct management of the COVID-19 pandemic. The current COVID-19 pandemic process is a public health problem rather than an intensive care problem. Moreover, this difficult period is a humanitarian crisis involving many crises, and there are very different sad stories around the world regarding the pandemic. Every step taken to manage this crisis should be in the frame of human rights and universal ethical principles.

\section{CONFLICT Of INTEREST}

The authors have no conflict of interest.

\section{we REFERENCES Cem}

[1] World Health Organization. Clinical management of severe acute respiratory infection (SARI) when COVID-19 disease is suspected. https://apps.who.int/iris/ handle/10665/331446 (accessed June 2020).

[2] World Health Organization. WHO Director-General's opening remarks at the media briefing on COVID-19- 11 March 2020. https://www.who.int/dg/speeches/detail/ who-director-general-s-opening-remarks-at-the-mediabriefing-on-covid-19---11-march-2020 (accessed June 2020).

[3] World Health Organization. COVID-19 Clinical management: living guidance. https://www.who.int/ publications/i/item/WHO-2019-nCoV-clinical-2021-1 (accessed March 2021).

[4] UNESCO. Statement on COVID-19: ethical considerations from a global perspective. https://unesdoc.unesco.org/ ark:/48223/pf0000373115 (accessed July 2020).

[5] UNESCO. Universal Declaration on Bioethics and Human Rights. https://en.unesco.org/themes/ethics-science-andtechnology/bioethics-and-human-rights (accessed July 2020).

[6] Büken NÖ. COVID 19 Pandemisinin Eşitlik, Özgürlük, Adalet Adına Düşündürdükleri Üzerine. Hekim Postası 2020; 101: 4-6.

[7] Coşkun S, Büken NÖ. COVID-19 Pandemic and Fair Allocation of Limited Medical Resources in Elderly People. In: Demirhan AE (ed). COVID-19 Pandemics and Ethics. 1st Ed. Ankara; Türkiye Klinikleri, 2021: 18-25.

[8] European Disability Forum. Updated Statement: Ethical Medical Guidelines in Covid-19 - Disability Inclusive Response. http://www.edf-feph.org/newsroom/news/ updated-statement-ethical-medical-guidelines-covid-19disability-inclusive-response-0 (accessed June 2020).
[9] United Nations. Convention on the Rights of Persons with Disabilities (CRPD), Article 11 - Situations of Risk and Humanitarian Emergencies. https://www.un.org/ development/desa/disabilities/convention-on-the-rightsof-persons-with-disabilities/article-11-situations-of-riskand-humanitarian-emergencies.html (accessed June 2020).

[10] World Medical Association. WMA Statement on Medical Ethics in The Event of Disasters. https://www.wma.net/ policies-post/wma-statement-on-medical-ethics-in-theevent-of-disasters/ (accessed June 2020).

[11] European Disability Forum. Open Letter to Leaders at the EU and in EU Countries: Covid-19 - Disability Inclusive Response. http://edf-feph.org/newsroom/news/openletter-leaders-eu-and-eu-countries-covid-19-disabilityinclusive-response\# (accessed June 2020).

[12] Republic of San Marino National Bioethics Committee. Answer to the Requested Urgent Opinion on Ethical Issues Regarding to the Use of Invasive Assisted Ventilation in Patients All Age with Serious Disabilities in Relation to Covid-19 Pandemic. https://www.sanita.sm/on-line/ home/bioetica/comitato-sammarinese-di-bioetica/ documents-in-english.html (accessed August 2020).

[13] Coşkun S, Büken NÖ. COVID-19 pandemisi ve etik. Pandemi ve Sağlık Hukuku Disiplinlerarası Yaklaşımla.1. Baskı. Ankara; Yetkin Yayınları, 2020: 45-78.

[14] Nacoti M, et al. At the epicenter of the Covid-19 pandemic and humanitarian crises in Italy: changing perspectives on preparation and mitigation. NEJM Catalyst Innovations in Care Delivery 2020; 1(2): 1-5.

[15] Emanuel EJ, et al. Fair allocation of scarce medical resources in the time of Covid-19. N Engl J Med 2020; 382: 2049-2055. 
[16] Turkish Medical Association. TTB Sağlık Çalışanlarının Risk Değerlendirmesi anketinde ikinci hafta sonuçları: Çalışma koşullarındaki olumsuzluklar sürüyor, sağlık çalışanlarının riski artıyor! https://www.ttb.org.tr/kollar/COVID19/ haber_goster.php?Guid=2f0107c8-731e-11ea-b12dd839943d748d (accessed August 2020).

[17] Coşkun S, Ünsal ÇZ, Büken NÖ. Covid-19 in Turkey. UNESCO Bioethical Voices, Newsletter of the UNESCO Chair in Bioethics, Haifa 2020; 20: 33-42.

[18] Turkish Medical Association. Salgın Ağırlaşıyor, Tükeniyoruz! Sağlık Çalışanlarının Sağlığı Toplumun Sağlığının Garantisidir. https://www.ttb.org.tr/ haber_goster.php?Guid=de4bd16c-e930-11ea-a71fa359d317f791 (accessed September 2020).

[19] Council of Europe. Lessons to be drawn from the ravages of the COVID-19 pandemic in long-term care facilities. https://www.coe.int/en/web/commissioner/-/lessons-tobe-drawn-from-the-ravages-of-the-covid-19-pandemicin-long-term-care-facilities (accessed August 2020).

[20] Turkish Medical Association. Salgınlara Yönelik Türk Tabipleri Birliği Etik Kurulu Görüşü. https://www.ttb.org. $\mathrm{tr}$ /makale_goster.php?Guid=4da9a49c-7674-11 ea-b329aa051764b049 (accessed August 2020).

[21] Aslan D, Büken NÖ, İlhan B. Yeni Koronavirüs Hastalığı (Covid-19) Deneyimi Üzerinden Pandemilerin Yönetimine İlişkin Değerlendirmeler. Sağlık ve Toplum 2020; COVID-19 Özel Sayısı: 94-97.
[22] Büken NÖ. COVID 19 Pandemisi ve Etik Konular. Sağlık ve Toplum 2020; COVID-19 Özel Sayısı: 15-26.

[23] The Lancet Editorial. Facing up to long COVID. Lancet 2020; 396 (10266): 1861.

[24] Norton A, et al. Long COVID: tackling a multifaceted condition requires a multidisciplinary approach. The Lancet Infectious Diseases 2021; 21: 601-602.

[25] Gorna R, et al. Long COVID guidelines need to reflect lived experience. The Lancet 2021397 (10273): 455-457.

[26] World Health Organization. Disability considerations during the COVID-19 outbreak. World Health Organization, 2020.

[27] World Health Organization. Maintaining essential health services: operational guidance for the COVID-19 context: interim guidance, 1 June 2020. World Health Organization, 2020.

[28] UNESCO. Unesco's Ethics Commissions' Call for Global Vaccines Equity and Solidarity, Joint Statement by the UNESCO International Bioethics Committee (IBC) and the UNESCO World Commission on the Ethics of Scientific Knowledge and Technology (COMEST), 24 February 2021. UNESCO, 2021. 